\title{
RADICAL CURE OF HERNIA IN YOUNG CHILDREN.*
}

BY D. KENNEDY, F.R.C.S.I., L.R.C.P.I. ;

Surgeon, Children's Hospital, Dublin.

Although the operation of "radical cure of hernia" seems to have been brought as nearly perfection as possible, and although most surgeons will not treat hernia in adults nowadays otherwise than by operation, yet young children with rupture are almost invariably left for treatment to the tender mercies of the instrument maker. The principal reasons for this appear to me to be, first, a hope that the wearing of a truss will in time effect a cure ; secondly, that the operation for radical cure in children is considered dangerous, and consequently should only be resorted to in very exceptional cases. Both these reasons I hold to be fallacious, and the hope of doing something to dispel that fallacy is my excuse for this communication to you to-night.

With regard to hernia in children being cured by wearing a truss, I am of opinion it is the exception, and not the rule. $\Lambda$ lthough a cure does occasionally result after years, I hold the treatment by operation is far less dangerous and far more surgical than treatment by trusses ; because so long as a child has a necessity for wearing a truss, so long is he exposed to the danger of the hernia becoming strangulated. And, besides this danger of strangulation, there are many and grave objections to a child being condemned to wear a truss for an indefinite period. Principally among these objections are(I) The truss causes a great deal of irritation about the groin, ending very frequently in troublesome eczema. This irrita-

* Read before the Section of Surgery of the Royal Academy of Medicine in Ireland, on November $1_{4}, 1902$. 
tion makes the child irritable and fretful, and consequently prevents thriving. Secondly, it is impossible to prevent the truss getting sodden with urine and fæces, and it becomes, in consequence, most objectionable and dangerous. Thirdly, the pressure of a truss, strong enough to keep up an ordinary hernia, prevents the muscles from developing in the neighbourhood of the inguinal canal, and consequently the abdominal wall is weakened, and large ruptures are liable to occur later in life. Fourthly, the expense of getting a truss frequently, as will have to be done as the child grows, is sometimes more than poor people can bear. But, the greatest of all objections to a truss in a child is that it is rarely effectual in keeping up a hernia, and then it does more harm than good I have met many such cases with hernia down, and kept down so long as the truss was worn.

These difficulties in connection with a young child wearing a truss are quite apparent to anyone who does much practice with children. And in proof of this I will refer you to the article on hernia in the recent surgery by Cheyne and Burghard. The writer of that article lays down that it is rarely an infant can wear an ordinary truss; consequently he recommends as a substitute, either a skein of worsted or a flannel bandage, to be changed, of course, aso ften as the child micturates. I think, gentlemen, this may be called grandmotherly surgery, and I am sure would not commend itself to me nor to the mothers of the children. The only solution is early operation, and what I mean by early, is, any time from the fourth month onward. The earlier done, the more perfect the cure, the less liability to recurrence, and the better development will there be of the abdominal muscles.

With regard to the dangers of the operation, they are to a large extent imaginary outside those which exist in the same operation with adults. I have carried out the opera- 
tion on at least sixty cases under five years of age, and at least a dozen of these were under twelve months old. I never had a death, never had any sepsis, beyond rarely a stitch abscess; the patients all left hospital between the ninth and fourteenth days, and although I have made many inquiries about the children since operation I know of no case of recurrence. What I have heard invariably was, that the children were much quiter and throve much better after than previous to operation.

I will not weary you with the details of these cases, as repetition becomes monotonous, but will give you some particulars of the younger ones.

CASE I.-T. K., æt. 5 months, came to me from Templemore last March. He was suffering from large double inguinal herniæ and phimosis. Both herniæ were present from birth, and the mother of the child told me a truss was quite ineffectual, though her doctor had procured her several. I admitted him to the private ward in Temple Street Hospital, and the day following operated on the right side. I found a large congenital hernia, with a very thick sac. I reduced the hernia, opened the sac, and then I found lying in the sac a very large vermiform appendix, Afraid kinking might occur if I reduced this appendix, and also afraid that it would hardly have room in the infant's abdomen, I resected it. I then, after dealing with the sac and canal, closed the wound and healing was perfect in eight days. Two days subsequently I operated on the left side, when I found an infantile hernia, the sac within sac variety, and at the same operation I performed circumcision, and ten days afterwards, that is, twenty days from his first operation, I showed the little patient here at the Academy, with his vermiform appendix in a bottle. Since that time he has never looked back.

CASE 2.-J J D. came to Temple Street Hospital, suffering from right inguinal hernia and.phimosis. The little patient was six weeks old, was emaciated, and the mother told me very irritable. He wore a truss which was not effectual in keeping up the hernia. 
The mother told me that she tried several trusses, without any better result. I circumcised the child, and gave instructions to have him back in three months' time. This was done, when I carried out a radical cure, and the child left on the ninth day, being then perfectly well, and under five months old.

The subsequent history of this child is interesting. Six months after operation I was sent for to go and see the child at his home, and was told the rupture had returned. I found a rupture, but on the other side. I again had him admitted to Temple Street Hospital, and I again carried out the radical cure with perfect success. Since that time, about eight months ago, he has had no trouble as far as I know. I was told that after birth the child had both ruptures, but that after a few weeks the left one disappeared, and only appeared again when the child began to make efforts to walk.

CASE 3.-Infant, æt. 6 months, sent to the Children's Hospital by Dr. Brew, of Bray. The child suffered from inguinal hernia. and a note was sent by the doctor saying that a truss was ineffect tual. I carried out a radical cure, and the child left hospital on the eleventh day, his wound completely healed.

CASE 4.-A girl, æt. 3, suffering from a large umbilical hernia, sent by Dr. Lyons, of Dunlavin, with a note requesting operation to be performed. I carried out the operation, resecting a large flap of skin with the hernial sac, vivified the edges of the opening in the abdominal wall, and united it by sutures of silkworm gut passed through all the layers, including the peritoneum, as after a laparotomy; the child left hospital in a fortnight perfectly well.

CASE 5.-A. D., æt. I6 months, came to the out-patient department of the Children's Hospital ; his mother said he was very ill. He suffered from left inguinal hernia, and was wearing a truss. On examination I found the hernia strangulated and admitted him at once to the hospital. Taxis failing to reduce the hernia, chloroform was administered, and I did herniotomy, at the same time carrying out the radical cure. The child was very ricktey- 
and emaciated, and could not be kept quiet after the operation. In consequence hæmorrhage occurred into the scrotum, and twenty four hours afterwards sloughing of the scrotal tissues appeared imminent. I again put him on the operation table, chloroform was again administered, and I removed the testicle, leaving the wound in the scrotum to granulate. His hernia wound healed by first intention, and he subsequently made a perfect recovery. I met two other cases of strangulated hernia, without any gangrene in the bowel being present, on both of which I operated, and both of which made an interrupted recovery. In these three cases of strangulated hernia, the patients wore trusses.

CASE 6.-Just three weeks ago, as 1 was leaving Temple Street Hospital on a Thursday morning, I was asked to see a child in the waiting room. The mother told me the child was ruptured and that he was ill all night; that he was vomiting, seemed to be in great pain, had no motion from the bowels for twelve hours in spite of a dose of castor oil, and passed no urine. On examination I found a very large scrotal hernia on the right side, completely irreducible. The infant looked very ill, and all the evidences of a strangulated hernia were present. I explained to the mother that I would have to administer an anæsthetic to the child, and that, failing a reduction of the hernia, I would operate. She left the hospital to get the consent of her husband, taking the infant with her, and did not return till the following morning. She was then agreeable to anything necessary being done with the child. When I saw him again, he looked dying. The mother told me all the symptoms had persisted during the previous day and night, and was most positive the child had passed no urine for thirty-six hours. I had him brought straight to the operating theatre and operated. I found a congenital hernia, strangulated at the neck of the sac. The bowel was discoloured but not gangrenous, and behind the bowel I found again an enormous vermiform appendix. After reducing the bowel I resected the vermiform appendix, closed the sac and the inguinal canal in the usual manner, and I am happy to tell you the child has made an. 
excellent recovery. It is only eight months old. In this operation, as in many of the others, I was ably assisted by my friend and colleague Dr. Lewis More O'Ferral. The operation lasted about forty minutes. There was no urine in the bladder at the time of operation.

From these cases you will see that there is little to be apprehended from carrying out the " radical cure" in infants. or young children. There are, however, a few points which appear to me to be essential to the success of the operation. First, no hæmorrhage should be allowed to take place; secondly, the operation should be carried out as quickly as possible, consistent with attention to details, and in a thoroughly aseptic manner; and, lastly, the anæsthetic should be properly administered. I especially insist that the child is not allowed to become half conscious at intervals during the operation, as I believe this to be productive of great shock. I have the child fully under the influence the whole time. I invariably use chloroform. Collapse after the operation has been conspicuous by its absence. Pain was not usually present to any great extent, and, if present, was easily relieved by small doses of chloral hydrate.

Contrary, I daresay, to your expectations, and, I may add, to custom, I am not going to describe or discuss any new method of dealing with either the sac or canal, which will in future be known as Kennedy's operation. I carry out as simple a procedure as possible. I never allow my skin incision to go to the scrotum; I ligature and resect the sac and use no means to fix it in the abdominal wall; I close the canal, after M'Ewen's method, and I do not displace the cord. I invariably circumcise the child. In dealing, however, with congenital hernia I met with an unexpected difficulty in my earlier cases. This was due to the complete union of the elements of the cord with the posterior wall of the hernial sac, making it impossible to separate one from the other. I have 
found this condition present in every case of congenital hernia I have operated on, and, in consequence, I have long since given up attempting to isolate the sac from the cord in these cases. This is a condition not usually dwelt on in text books, or by men who have described methods of " radical cure of hernia." It seems to me impossible in these cases to carry out the twisting or invaginations of the sac, which are so elaborately described by some operators, or even to have the sac ligatured in its entirety. I would like to have the opinion of the members of this section of the Academy as to what is best to be done in these cases. I draw down the sac as well as possible after freeing it round the internal abdominal ring. I transfix it, and pass a ligature in front of the cord, as high up as I can get, I then divide the sac transversely above the scrotum, leave the lower part to form a tunica vaginalis, and dissect away all I can of the part lying in the inguinal canal below the ligature. This practically leaves the posterior wall of the sac as it was before.

With regard to the after-treatment I have little to say. I cover the dressing and bandage with protective. There is usually no need to change the dressing oftener than every second or third day. I usually fix the child in a Bryant's splint ; this keeps him quiet, and materially assists the nursing. I remove the stitches on the sixth or eighth day, and, needless to tell you, I do not recommend a truss to be worn for any time whatever.

In conclusion I may say that I did not adopt this method of operating on almost all cases of hernia in children without giving treatment by trusses a fair frial. The results were most disappointing. It was a continuous go from me to the truss maker, and from the truss maker back again to me. On the other hand, the more cases I have operated on, the more pleased I am with the results, and the more determined I am to "throw" trusses, like " physic, to the dogs." 